\title{
Trump Administration Begins to Recognize the Loss of Scientific Integrity: Refuting a Political Hit job
}

\author{
J. Marvin Herndon, Ph.D. \\ Transdyne Corporation, San Diego, California, USA;
}

\begin{abstract}
A recent $P L O S O N E$ article utilized tabulations of opinions obtained from federal scientists to assert "perceived losses of scientific integrity under the Trump Administration." The article presupposes the wide-spread existence of scientific integrity among federal scientists, which I refute based upon documented $40+$ years' experience making fundamental scientific discoveries which the scientific establishment systematically ignores and in instances has attempted to suppress. These discoveries include, but are not limited to: Earth's nickel-silicide inner-core composition, the physical impossibility of both mantle convection and Earth-core convection; recognition that Earth's early formation as a Jupiter-like gas giant makes it possible to derive virtually all geological and geodynamic behavior of our planet, including origin of continents and oceans, ocean floor topography, origin of mountains characterized by folding, primary initiation of fjords and submarine canyons, and two previously unanticipated potentially variable energy sources - nuclear fission and stored energy of protoplanetary compression; nuclearfission-reactor origin of planetary magnetic fields, including the geomagnetic field; thermonuclear ignition of stars and the reason why the multitude of galaxies display just a few patterns of luminous stars; and, particulate pollution, not greenhouse gases, as the main cause of local and global warming. A scientific community, apparently suffering from Integrity Deficit Syndrome, cannot be expected to provide a truthful assessment, especially when queried about the actions of a president who might change the science landscape under which they flourish.
\end{abstract}

Keywords: Blacklisting; Science suppression; Science integrity loss; arXiv; Science improvement.

\section{INTRODUCTION}

A recent article in PLOS ONE [1] entitled "Perceived Losses of Scientific Integrity under the Trump Administration: A Survey of Federal Scientists" presents a one-sided and pejorative view of the Trump Administration. The article presupposes the wide-spread existence of scientific integrity among federal scientists. There exists a close; some might say insidious, relationship between government scientists and government-funded academic scientists. I challenge the supposition of scientific integrity among both government and academic scientists, in the physical sciences at least, and thereby refute the conclusions presented by Goldman et al. [1]. Some of my experiences publishing world-class scientific discoveries in the physical sciences [2], documented over a period 
Herndon, J. M. (2020). Trump Administration Begins to Recognize the Loss of Scientific Integrity: Refuting a Political Hit job. Advances in Social Sciences Research Journal, 7(5) 283-303.

of more than four decades, call into question the entire concept of scientific integrity with respect to both government scientists and government-funded academic scientists in that domain. Consequently, their opinions, collected by Goldman et al. [1], are an invalid basis to legitimately assert "Perceived Losses of Scientific Integrity under the Trump Administration." The PLOS ONE [1] article might be considered by some as a political hit job.

The criterion for truth is different for science than for other human endeavors such as politics which embraces consensus conformity. In science, when a new idea is published, it should be discussed and debated. If the idea or observation is found to be in error, it should be refuted, ideally in the journal of original publication; otherwise, it should be cited in subsequent literature on the subject [3]. In the following, I document wide-spread, institutional failure of scientists to maintain that criterion for truth in the physical sciences, which, I allege, constitutes failure to maintain scientific integrity.

Prior to World War II there was essentially no government support for civilian science. That changed in 1950 with the establishment of the U.S. National Science Foundation (NSF). From the outset, that organization, by the science-funding principles it established, which were adopted by subsequent agencies, was responsible for slowly trivializing civilian science and eroding scientific integrity [4].

The NSF-originated idea that science-funding proposals should be reviewed anonymously by the proposers' competitors was most egregious of the science-funding principles [4]. It does not take a rocket scientist to figure out that, if you criticize another's science, there may be anonymous retribution via proposal reviews. Nearly seventy years' application of that flawed methodology has perverted scientific integrity over a broad spectrum of the physical sciences. One result is that government-funded scientists, driven by career-fear, generally accept without question consensusapproved fundamental concepts, and fail to cite contradictions thereto.

Fundamental scientific concepts by definition underpin and provide the bases upon which subsequent scientific developments are built. The realization that nature can be better described differently and more precisely than by extant fundamental scientific concepts leads to paradigm shifts [5], at least if there is scientific integrity. If someone publishes in the scientific literature an important contradiction to a fundamental concept, then as stated above, it should be refuted or otherwise subsequently cited; if ignored, that is indicative of a scientific community devoid of integrity.

In the following, I describe various fundamentally new scientific concepts that were neither refuted nor cited, and which in a few instances there were blatant attempts made at suppression. Collectively, these documented occurrences call into question the integrity of broad-swaths of scientists, institutions, and government agencies throughout the physical sciences. Consequently, I suggest that the above cited PLOS ONE [1] article perhaps instead should have been entitled "Trump Administration Begins to Recognize Loss of Scientific Integrity." 


\section{SYSTEMATICALLY IGNORED FUNDAMENTAL CONCEPTS:}

\section{EARTH'S INTERNAL COMPOSITION}

\section{Earth's Inner Core Composition}

In 1936, Inge Lehmann [6] discovered, i.e. reasoned the existence of, the inner core to explain earthquake waves reflected into the "shadow zone." In 1940, Birch [7] reasoned from extant data that the inner core must be partially-crystalized iron metal. In 1979, I published a contradictory inner core composition of nickel silicide [8] and received a highly-complementary letter from Inge Lehmann (Figure 1).

p.t.S bakkevej 11
2840 Holte, Denmark
August 17, 1979

Dr. J.M.Herndon

Department $6 f$ Chemistry

University of California, San Diego

La Jolla, California 92093

Dear Dr. Herndon,

Thank you for sending me your very interesting paper:

Earth's nickel silicide inner core.

I admire the precission of your reasoning based on available information, and I congratulate you on the highIy important result you have obtained.

It has been a special pleasure to be informed in advatce of publication. I shall be interested to note the reactions of other geophysigists.

With kind regards

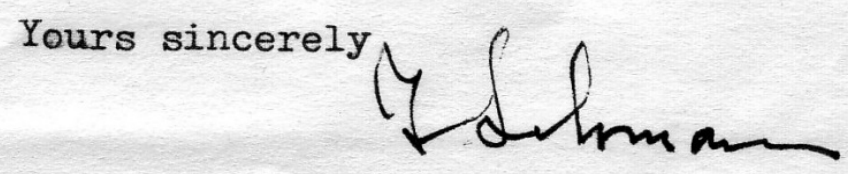

Inge Lehmann

Figure 1. Congratulatory letter from Inge Lehmann, discoverer of the Earth's inner core. 
Herndon, J. M. (2020). Trump Administration Begins to Recognize the Loss of Scientific Integrity: Refuting a Political Hit job. Advances in Social Sciences Research Journal, 7(5) 283-303.

After my inner-core article's publication in 1979, there was no discussion and debate. Moreover, my NASA grant, which the paper acknowledged, was not renewed without good reason. I was 'excommunicated' and over the following decades there were numerous citations of the 1940 partially-crystalized inner core idea [7,9], without refuting or citing my nickel silicide inner core concept [10-13].

\section{Endo-Earth Composition}

Ordinary chondrite meteorites, superficially resembling Earth, have long figured into ideas of its composition. Beginning in 1980, I related the seismically-determined parts of the Earth to corresponding parts of primitive oxygen-poor enstatite chondrites, as shown in Table 1, thereby providing compelling evidence that the inner $82 \%$ of Earth resembles an enstatite chondrite [14$19]$.

Table 1. From [19]. Fundamental mass ratio comparison between the endo-Earth (lower mantle plus core) and the Abee enstatite chondrite. Above a depth of $660 \mathrm{~km}$, seismic data indicate layers suggestive of veneer, possibly formed by the late addition of more oxidized chondrite and cometary matter, whose compositions cannot be specified with certainty at this time.

\begin{tabular}{|c|c|c|}
\hline FUNDAMENTAL EARTH MASS RATIO & EARTH RATIO VALUE & ABEE RATIO VALUE \\
\hline Lower Mantle to Total Core & 1.49 & 1.43 \\
\hline Inner Core to Total Core & 0.052 & $\begin{array}{l}\text { Theoretical } \\
0.052 \text { if } \mathrm{Ni}_{3} \mathrm{Si} \\
0.057 \text { if } \mathrm{Ni}_{2} \mathrm{Si}\end{array}$ \\
\hline Inner Core to Lower Mantle plus Total Core & 0.021 & 0.21 \\
\hline D" to Total Core & 0.09 & $0.11 *$ \\
\hline ULVZ** of D" CaS to Total Core & $0.012 * * * *$ & $0.012^{*}$ \\
\hline \multicolumn{3}{|c|}{$\begin{array}{c}\text { Notes: * = avg. of Abee, Indarch, and Adhi-Kot enstatite chondrites } \\
\text { D" is the "seismically rough" region between the fluid core and lower mantle } \\
* * \text { ULVZ is the "Ultra Low Velocity Zone" of D" } \\
\text { D }^{* * *} \text { calculated assuming average thickness of } 200 \mathrm{~km} \\
* * * \text { calculated assuming average thickness of } 28 \mathrm{~km} \\
\text { data from [20-22] }\end{array}$} \\
\hline
\end{tabular}

One major consequence of the oxygen-poor composition of the endo-Earth is that a portion of oxygen-loving elements became incorporated in the core during Earth formation. These include silicon, magnesium, calcium and, notably, uranium. Silicon combined with nickel to form the nickelsilicide inner core, calcium and magnesium combined with sulfur and floated to the top of the core, and uranium ended up at the very center of Earth [14-19].

\section{Oxygen-poor Primitive Matter}

The matter comprising the enstatite chondrites formed under oxygen-starving conditions, which had been a mystery until I discovered primordial condensation at high temperatures and high pressures with prompt isolation of the condensate would naturally lead to that oxygen-starved composition [23]. The fundamental mass ratio identities, shown in Table 1, demonstrate that the matter of the endo-Earth formed similarly [23-25]. 


\section{SYSTEMATICALLY IGNORED FUNDAMENTAL CONCEPTS: EARTH'S PROTOPLANETARY FORMATION}

In the late 1960s and early 1970s, low-pressure nebula computational models were made to explain minerals characteristic of ordinary chondrites, (wrongly) thought to be the substance of planets, as condensates from a gas phase of solar composition at low pressures and low temperatures [26-28]. In 1978, for that system I demonstrated that equilibrium could be attained only at a single low temperature, if at all, and the result would be highly oxidized condensate more resembling primitive carbonaceous chondrites [29]. My work was neither refuted nor cited for decades as low-pressure equilibrium condensation models continued to be made [30-32]. Moreover, failure to cite my work [23-25] prevented NASA Messenger Mission planetary scientists from understanding an unusual, but important feature observed on the surface of planet Mercury (Figure 2).

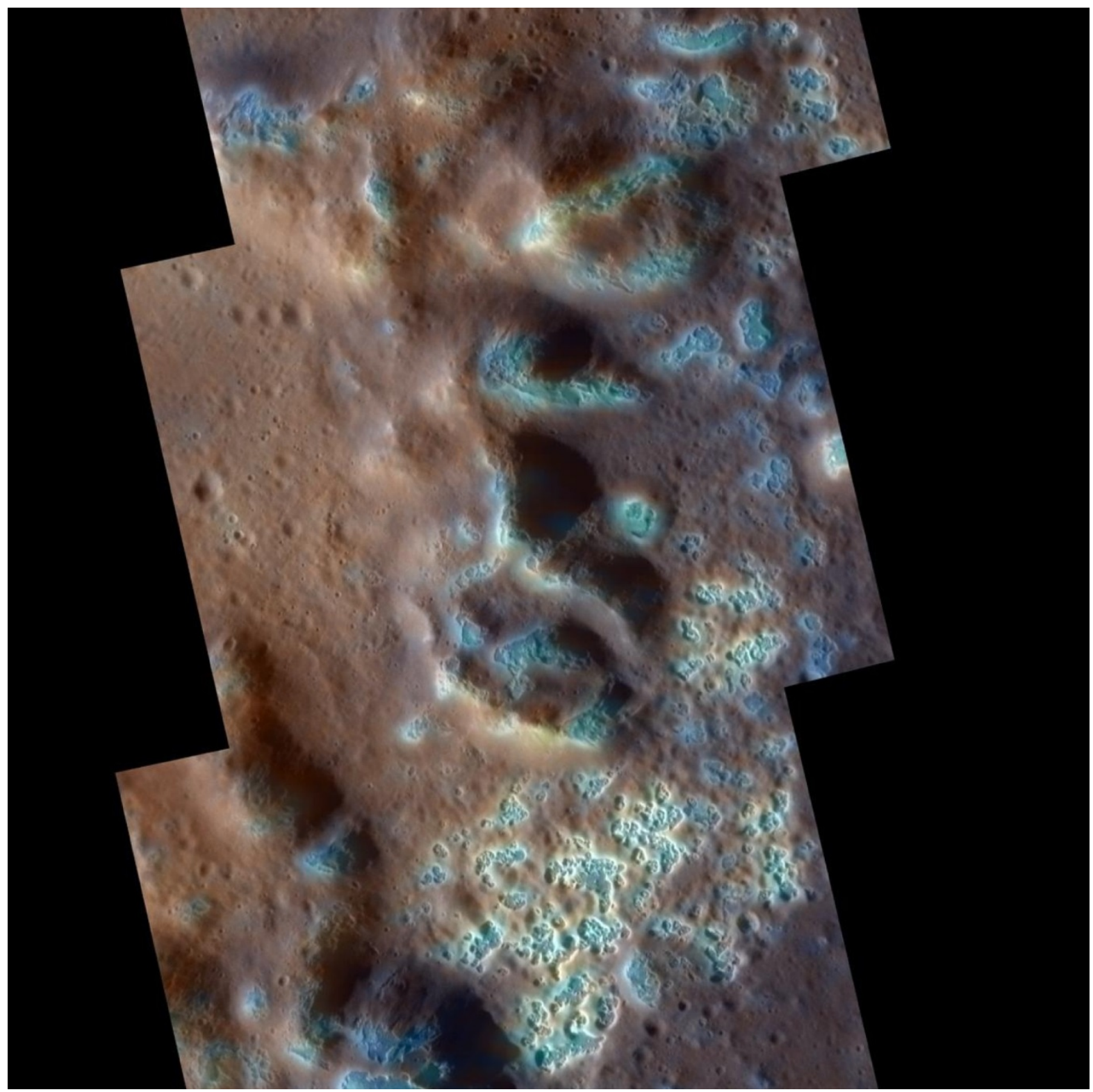

Figure 2. Project Mercury photo showing pits, surrounded by shiny material, observed on Mercury's surface caused by exhaled gas. 
Herndon, J. M. (2020). Trump Administration Begins to Recognize the Loss of Scientific Integrity: Refuting a Political Hit job. Advances in Social Sciences Research Journal, 7(5) 283-303.

NASA scientists claimed the planetary formation models they considered could neither account for the quantity of gas-release necessary to form the pits nor could explain the shiny material [33]. NASA scientists and NASA-funded scientists, however, have a major integrity deficit: They systematically refuse to cite my relevant discoveries, as I describe with numerous examples in my book, NASA: Politics above Science [34].

The iron comprising Mercury's core condensed as a liquid at high temperatures and pressures and dissolved copious amounts of hydrogen. As Mercury's core solidified, it expelled the hydrogen, which produced the pits and reduced iron sulfide to the metal, producing the shiny material [35]. This logical, causally-related explanation stemmed from my understanding of the relationship between enstatite chondrite matter and that of the endo-Earth, and the origin of the oxygenstarvation process $[23-25,36]$.

\section{SYSTEMATICALLY IGNORED FUNDAMENTAL CONCEPTS: EARTH'S NUCLEAR FISSION GEOREACTOR}

Applying Fermi's nuclear reactor theory [37], in 1993, I first published the concept and demonstrated the feasibility for the existence of a self-sustaining, natural, nuclear fission reactor at Earth's center [16, 38-40], schematically illustrated in Figure 3. This concept was greatly extended by sophisticated nuclear reactor numerical simulations made at Oak Ridge National Laboratory, which provided compelling evidence of georeactor existence [41, 42] vis-á-vis helium fission products which solved one of the great unknown problems in geophysics.

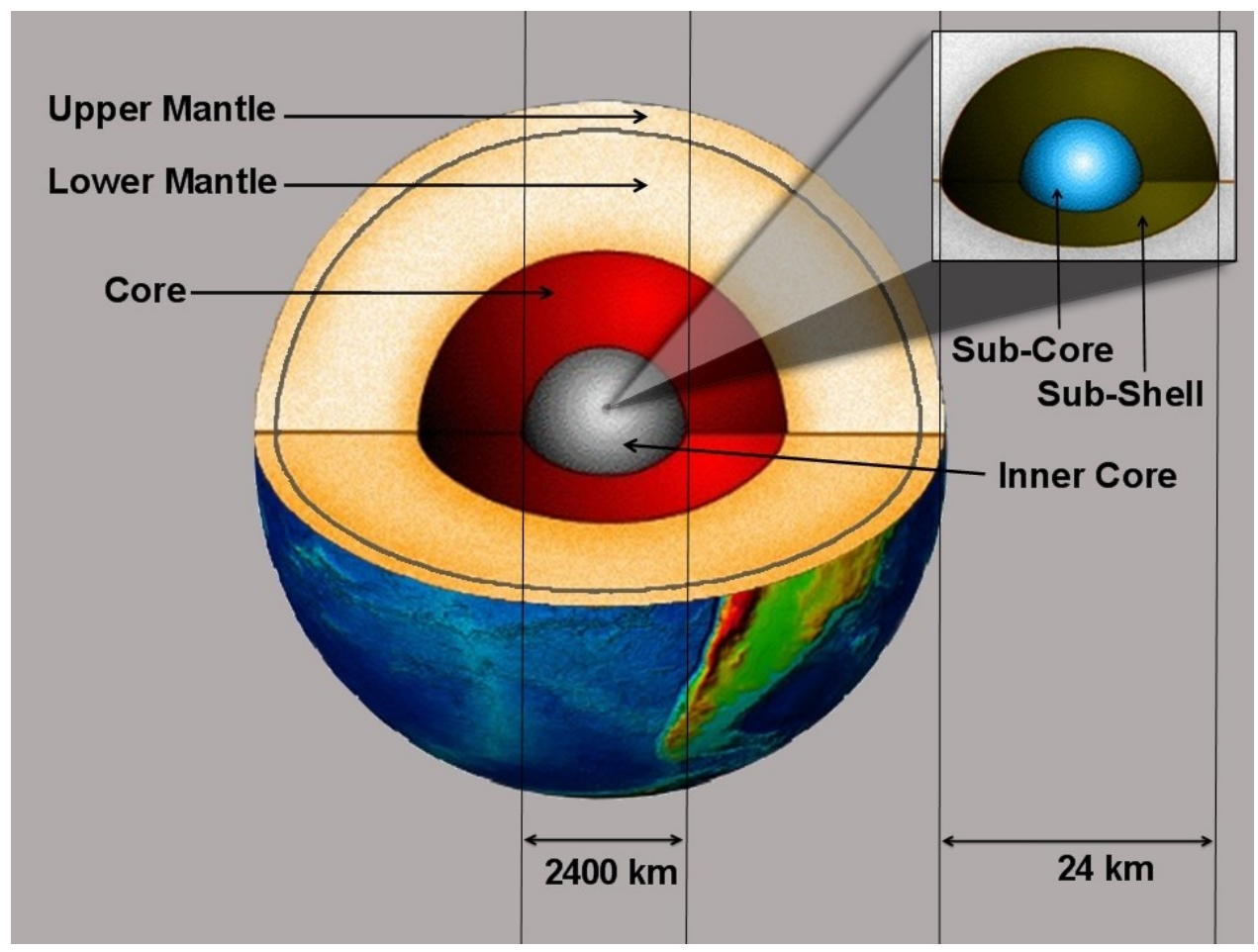

Figure 3. Schematic representation of Earth's nuclear georeactor. The nuclear sub-core is surrounded by the nuclear- waste sub-shell. For more information see [19].

Helium-3 observed in volcanic rocks was a mystery because no process was known that could account for its production, so it was thought to be a primordial component of Earth or to have 
arrived on cosmic dust and then was 'subducted.' The Oak Ridge calculations not only solved that problem, but revealed major integrity-corruption at the National Academy of Sciences [43] as four members unwarrantedly attempted to suppress its publication, but failed in their efforts [41].

There was no kudos for solving the deep-Earth helium problem, geophysicists just moved on to other endeavors, but now a new generation has begun the same trapped primordial helium nonsense [44]. Does no one read the literature? Understanding extant relevant scientific literature is part of scientific integrity. Now, literature searches are easy with computers. When I started in science I would spend days in the library searching print-journals without benefit of computers.

\section{SYSTEMATICALLY IGNORED FUNDAMENTAL CONCEPTS: NUCLEAR GENERATED PLANETARY MAGNETIC FIELDS}

In a series of papers beginning in 1939, Elsasser proposed that the geomagnetic field is generated by a convection-driven mechanism in Earth's fluid core [45-47]. Convection is a familiar process: Heat a pan of water on the stovetop, add a few tea leaves or celery seeds to reveal water motion, and observe the bottom to top, top to bottom motion before it boils. This is convection.

In a submission to Physical Review Letters in 2009, I described why convection is physically impossible in the Earth's fluid core [48], but that paper was suppressed, rejected for no good reason including by one or two members of the National Academy of Sciences. Subsequently, I published the idea that the geomagnetic field and (more generally) magnetic fields in planets and in large moons are generated by planetocentric nuclear fission reactors [18, 19, 36, 49, 50]. Without attempting to refute my work, geoscientists still make models of physically-impossible Earth-core convection to explain geomagnetic field production where it cannot occur [51, 52].

\section{SYSTEMATICALLY IGNORED FUNDAMENTAL CONCEPTS: EARTH'S SURFACE DYNAMICS}

Many geophysicists assume that the observation of basalt being extruded from mid-oceanic ridges, creeping across the ocean bottom, and disappearing into trenches implies mantle convection, which is the basis for plate tectonics theory. However, I have shown that mantle convection is physically impossible [18]. Consequently, plate tectonics cannot be a correct theory. I have set forth a fundamentally different theory, Whole-Earth Decompression Dynamics (WEDD), that follows logically and causally from Earth's initial formation as a Jupiter-like gas-giant $[19,36,49,50,53$ 59].

Earth formed initially as a gas-giant planet similar in mass to Jupiter, with a rocky-kernel about twothirds the diameter of present-day Earth. When thermonuclear reactions in the sun ignited, the violent T-Tauri winds stripped away the Earth's gases leaving a compressed rocky planet with a contiguous surface. As georeactor heat began replacing the lost heat of crystallization, planetary decompression began, powered by georeactor-produced energy and the much greater stored energy of protoplanetary compression. As decompression proceeds, two actions occur that account for most of Earth's surface geology and geodynamics: Surface area increases and surface curvature adjusts. Surface area increases by the formation of cracks. Cracks with underlying heat sources, typically lying along mid-ocean ridges, produce basalt that flows by gravitational creep until it falls into and in-fills cracks without underlying heat sources. Surface curvature adjustments occur primarily by continental crust buckling, breaking, and falling over, producing mountains 
Herndon, J. M. (2020). Trump Administration Begins to Recognize the Loss of Scientific Integrity: Refuting a Political Hit job. Advances in Social Sciences Research Journal, 7(5) 283-303.

characterized by folding, and secondarily by the formation of peri-continental tears, that became fjords and submarine canyons. This is Whole-Earth Decompression Dynamics in a nutshell.

\section{SYSTEMATICALLY IGNORED FUNDAMENTAL CONCEPTS: THERMONUCLEAR IGNITION OF STARS}

At the dawn of the $20^{\text {th }}$ century, one of the great mysteries in science was the nature of the energy source that powers the sun and other stars. By the end of 1938, physicists had discovered that thermonuclear fusion reactions, like the example shown in Figure 4, likely are that unknown energy source [60-63].

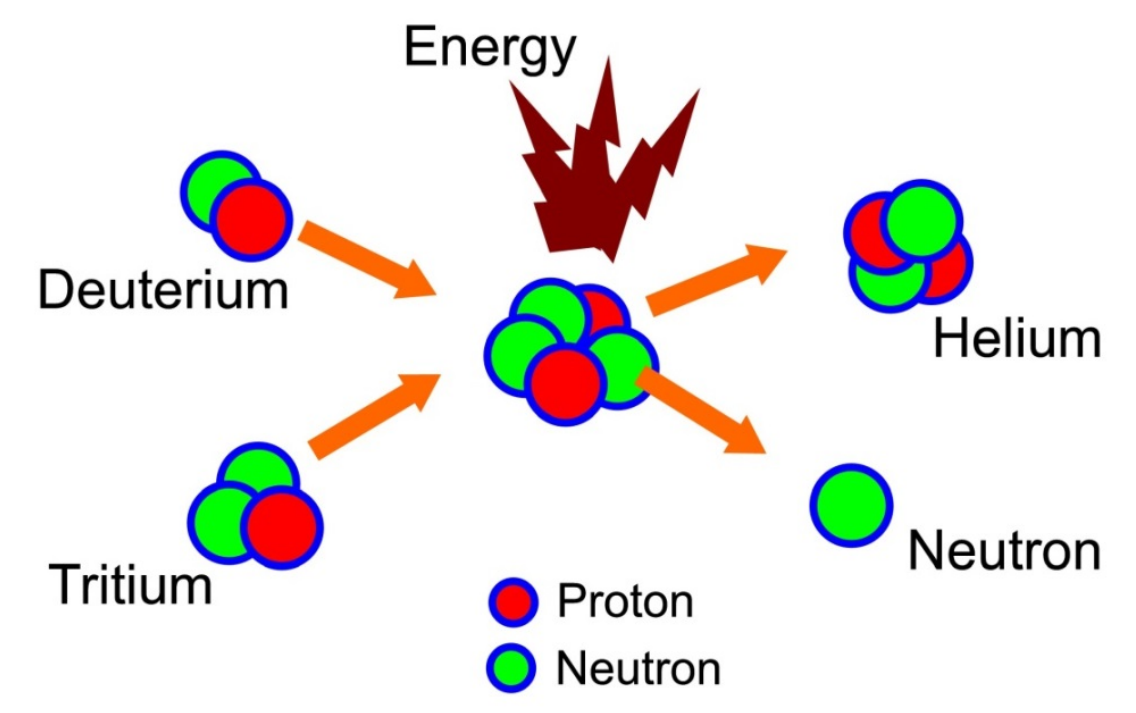

Figure 4. Schematic representation of a nuclear fusion reaction.

Thermonuclear reactions are called thermonuclear because temperatures of about one million degrees Celsius are required. At the time thermonuclear reactions were envisioned for powering stars, the only energy source imagined capable of initiating those reactions was the gravitational potential energy released during stellar collapse to form the star. But there are problems with that concept, principally by radiation loss from the surface, which is a function of the fourth power of temperature. Rather than asking what is wrong with the concept, astrophysicists just tweaked their models [64-66].

Stars are like hydrogen bombs held together by gravity. The thermonuclear fusion reactions of each hydrogen bomb detonated are ignited by nuclear fission chain reactions, illustrated schematically in Figure 5. 


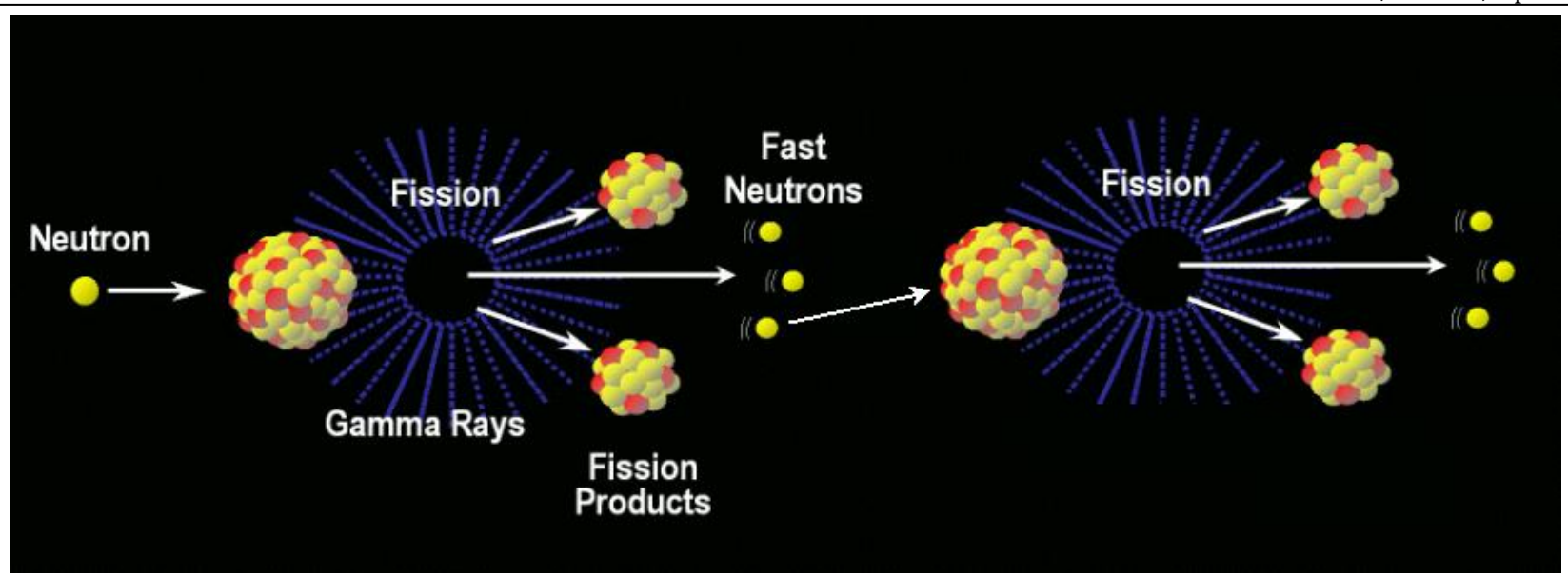

Figure 5. Schematic representation of uranium nuclear fission chain reactions.

In 1994, I published in the Proceedings of the Royal Society of London my concept that thermonuclear reactions in stars are ignited by nuclear fission chain reactions [38]. For decades that paper was neither refuted nor cited. Instead the astrophysics community continued to promulgate themes and variations on the old and flawed gravitational collapse idea [67-69]. When exposed to a fundamentally new concept, a credible scientist would investigate its potential implications. That is what I did, but by not doing similarly astrophysicists missed the opportunity to make fundamental discoveries.

\section{SYSTEMATICALLY IGNORED FUNDAMENTAL CONCEPTS: NATURE OF DARK MATTER IN THE UNIVERSE}

The observed patterns of luminous galactic stars, evident for example as spiral galaxies, represent dynamically-unstable configurations. These unstable patterns of luminous stars are thought to be held in place by halos consisting of massive amounts of non-luminous, dark matter, 10-100 times as massive as the luminous stars [70]. Astronomers and astrophysicists search for particles of dark matter while ignoring my published suggestion that follows logically and causally from the thermonuclear ignition of stars by nuclear fission chain reactions [38].

The circa 1930s idea that stars are ignited as a consequence of gravitational collapse implies that all stars more massive than brown dwarfs ignite as they form, which would mean that all nonbrown-dwarf galactic stars would be luminous. However, there is no evidence that gravitational collapse alone is sufficient to ignite stars, but, on the other hand, the detonation of every thermonuclear fusion device constitutes experimental evidence that nuclear fission chain reactions can ignite thermonuclear fusion reactions.

Thermonuclear ignition of stars by nuclear fission admits the possibility of non-ignition of stars that are devoid of fissionable elements. A one-solar-mass dark star would be about the size of Earth [71]. I suggested that the galactic dark matter is composed of dark stars, devoid of the fissionable elements necessary for ignition [38]. For 25 years that concept was neither refuted nor cited while massive amounts of taxpayer funds were spent by astronomers and astrophysicists who were looking the other way. 
Herndon, J. M. (2020). Trump Administration Begins to Recognize the Loss of Scientific Integrity: Refuting a Political Hit job. Advances in Social Sciences Research Journal, 7(5) 283-303.

\section{SYSTEMATICALLY IGNORED FUNDAMENTAL CONCEPTS: THERMONUCLEAR IGNITION OF DARK GALAXIES}

A deep-field view from the Hubble Space Telescope, upper portion of Figure 6, shows that the universe consists of numerous galaxies, which have variations on just a couple of characteristic luminous-star distributions, notably spiral and spiral-bar galaxies, two examples of which are shown in the lower portion of Figure 6.

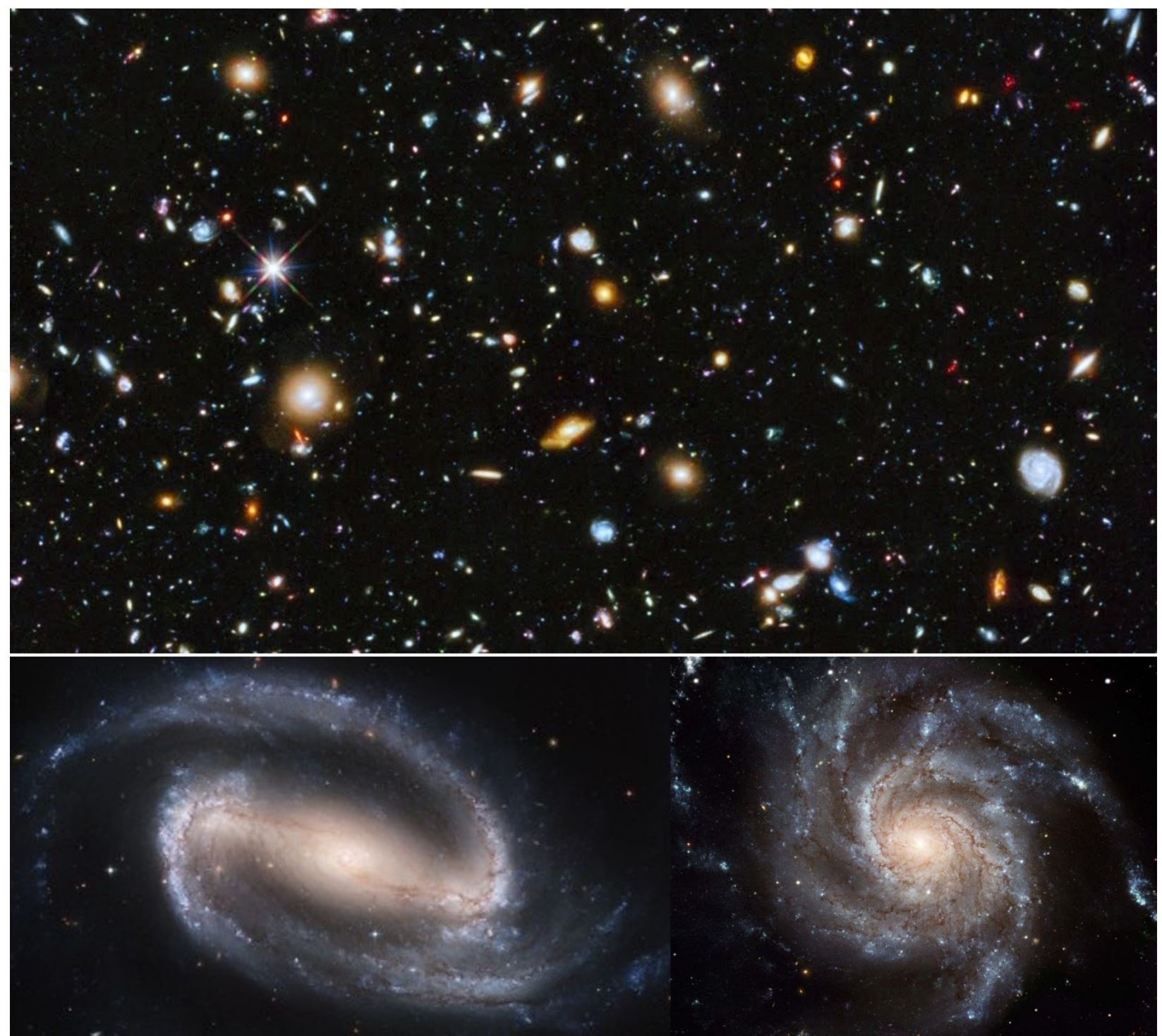

Figure 6. Upper: Hubble Space Telescope deep-field view showing thousands of galaxies displaying variations on just a couple of luminous-star distribution-patterns, illustrated below. Lower: Bar spiral galaxy left (NGC 1300); Spiral galaxy right (M101).

Little is known about the highly energetic processes that take place in the massive cores of galaxies. Occasionally, jets are observed shooting out from galactic centers, examples of which are shown in the upper portion of Figure 7. From left to right, those jets are 4,000, 10,000, and 865,000 light years long. Jets can be single or bi-directional. I suggested that, when the matter of these jets encounters galactic dark stars, the dark stars are seeded with fissionable elements, which undergo nuclear fission chain reactions that ignite thermonuclear fusion reactions turning the dark stars into 
luminous stars. Thus, the pattern of luminous stars in a galaxy is a consequence of the jets from its center [72-75].

The lower portion of Figure 7 provides compelling evidence of the correctness of my thesis by showing examples of how a dark galaxy appears after it shoots out its first jet.

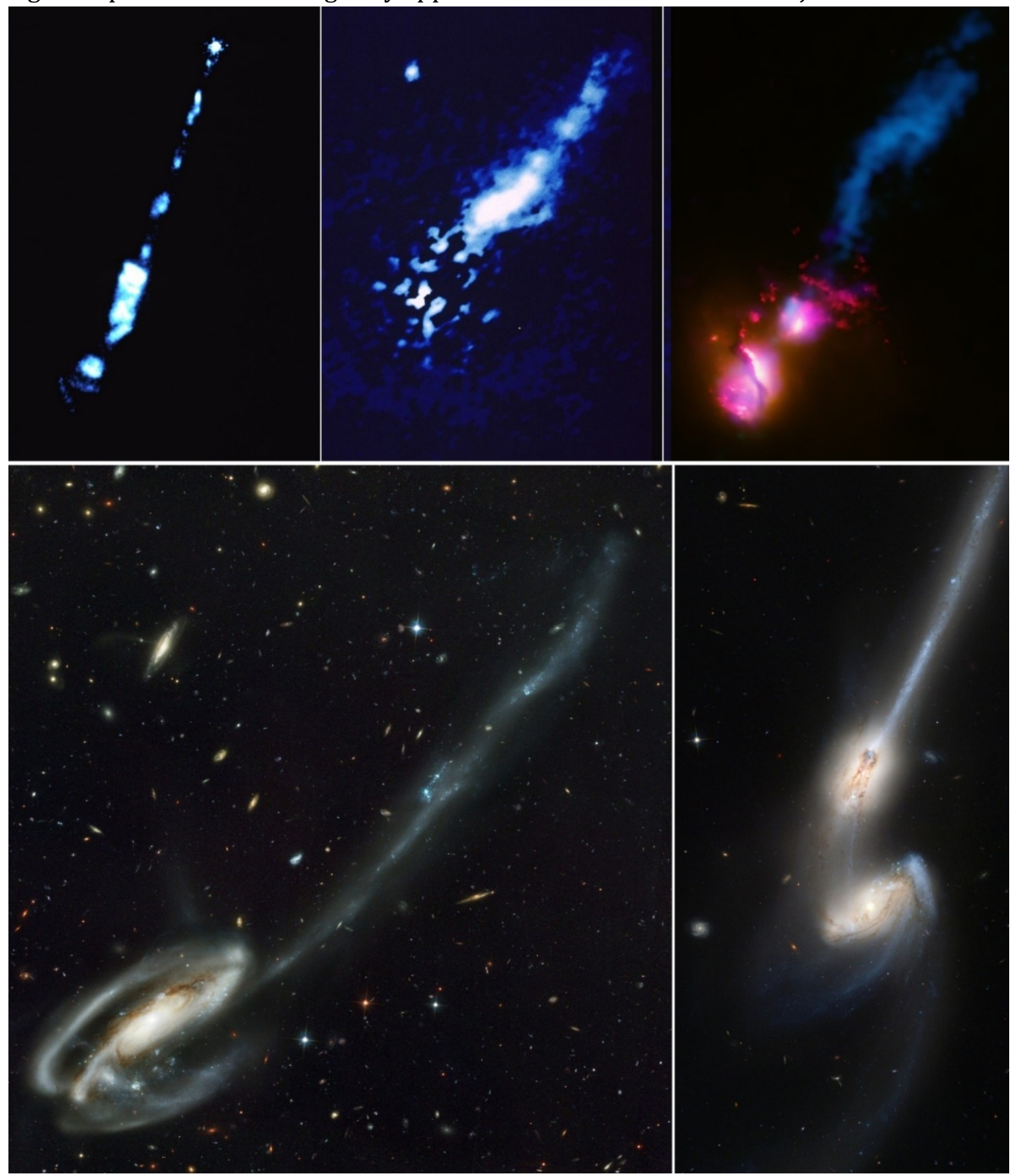

Figure 7. Upper: Three galactic jets, left to right, 4,000, 10,000, 865,000 light years in length. Lower: Galaxies, UGC 10214 left, NGC 4676 right, showing how dark galaxies appear when they begin to produce galactic jets which seed the dark stars they encounter with fissionable elements that then ignite their thermonuclear fusion reactions. 
Herndon, J. M. (2020). Trump Administration Begins to Recognize the Loss of Scientific Integrity: Refuting a Political Hit job. Advances in Social Sciences Research Journal, 7(5) 283-303.

When an important new fundamental concept, such as just described, that accounts in a logical, causally-related manner for the formation and distribution-pattern of luminous galactic stars as well as the associated dark matter component, astrophysicists should try to refute, and if unable should cite where appropriate. That did not happen; the astrophysics community systematically ignored the work and continued to stumble in the dark [76-78]. My submitted manuscripts to Astrophysical Journal Letters received disparate treatment, and were unwarrantedly rejected [43, $79,80]$. There is a major integrity problem.

\section{SYSTEMATICALLY IGNORED FUNDAMENTAL CONCEPTS: HOT-JUPITER EXOPLANETS AND PLANET MIGRATION}

The discovery of planets orbiting stars other than Sol, our sun, should have opened a new era of objectivity in the astro-community. But in my experience that was not the case. Because stars were (wrongly) thought to ignite by gravitational collapse upon formation, planets were thought to form after stellar ignition by accumulation of dust and rocks. The gas-giant Jupiter was thought to have formed beyond a hypothetical snow line [81] where presumably temperatures were sufficiently low-enough for gases and ices to condense. Then Hot-Jupiter exoplanets were found orbiting stars other than Sol. These exoplanets radiated vast amounts of energy, which others could not explain, but I proposed a reasonable explanation [79].

How did astrophysicists explain gas-giant exoplanets that were found as close to their star as Earth is from the sun? They invented the concept of planet migration, which I refuted [80].

My submitted manuscripts to Astrophysical Journal Letters received disparate treatment, and were unwarrantedly rejected $[43,79,80]$. Those actions deprived me of the credit I earned from those discoveries, harmed my career prospects, and cheated taxpayers. Those actions hide new, important concepts from the scientific community and from government-funding officials. There is a major integrity problem. I was able to post pre-prints of those papers on an author self-posting archive, but soon thereafter I was blacklisted by that archive.

\section{SCIENTISTS BLACKLISTED}

By the 1990s corrupt scientists, acting under the guise of reviewing papers for publication, were causing delays of up to two years or preventing publication. In 1995, the National Science Foundation (NSF) funded the development at Los Alamos Scientific Laboratory of an author selfposting archive where physicists could post pre-prints that others throughout the world could view almost immediately. But from the beginning, there were allegations of blacklisting [82]. On or about 2001 NSF gave Cornell University nearly one million dollars to take possession of the archive, arxiv.org. The archive developers moved with the archive to Cornell. Blacklisting intensified.

University and government scientists (email ending in .edu and gov) could post without interference. But others with different email-endings were subject to disparate treatment. Before posting, an individual in that category was required to obtain an endorsement from someone qualified to endorse. Soon after I complained to the American Astronomical Society about the unwarranted suppression of my papers by one of the journals they publish, Astrophysical Journal Letters, I found I was blacklisted by arxiv.org. Blacklisting means that when I attempt to post a paper, unknown "moderators", not reviewers, decide whether it would be allowed to post under an 
inappropriate category, where it would not be noticed, such as General Physics, or whether it would not post at all. I was also stripped of my ability to endorse others (Figure 8).

\title{
Before Being Blacklisted
}

J. Marvin Herndon is qualified to endorse.

\section{J. Marvin Herndon is qualified to endorse.}

New Concept for Internal Heat Production in Hot Jupiter Exo-Planets

J. Marvin Is registered as an author of this paper.

Herndon: Can endorse for astro-ph, physics.ed-ph, physics.gen-ph, physics.geo-ph, physics.hist-ph and physics.space-ph. (why?)

\section{After Being Blacklisted}

No authors of 1306.6891 can endorse.

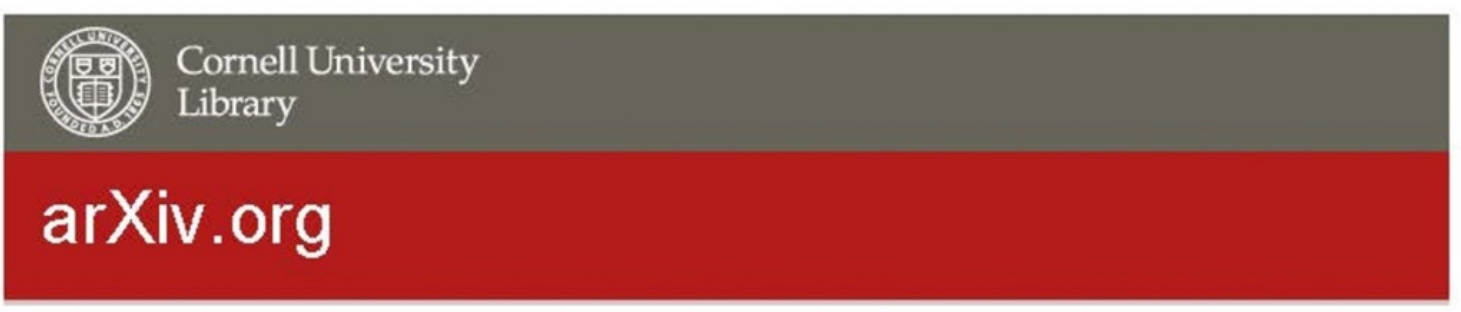

No authors of 1306.6891 can endorse.

\author{
New Indivisible Planetary Science Paradigm \\ J. Marvin Herndon: Is registered as an author of this paper. \\ Not currently an endorser. (why?)
}

Figure 8. Upper shows my submission that was posted in the category of Astrophysics and the various areas in which I was qualified to endorse before being blacklisted. Lower shows a submission that was allowed to post, but only in the inappropriate category General Physics and shows that I was no longer allowed to endorse others.

Cornell University receives millions of dollars annually from government contracts and grants, yet hides competitors' work. I complained to more than one of Cornell's provosts, officers of the Corporation, but the typical response was to send my complaint to the very people I filed the complaint against.

Shortly before an election, one U. S. Congressman filed a complaint with the U.S. Asst. Attorney General for Antitrust. But then Barack Obama was elected and his Department of Justice quelled the complaint. More scientific integrity than the Trump Administration? No way! 
Herndon, J. M. (2020). Trump Administration Begins to Recognize the Loss of Scientific Integrity: Refuting a Political Hit job. Advances in Social Sciences Research Journal, 7(5) 283-303.

\section{POOR SCIENCE AND DEFICIENT INTEGRITY}

The United States Geological Survey (USGS), according to its mission statement, "serves the nation by providing reliable scientific information to describe and understand the earth; minimize loss of life and property from natural disasters; manage water, biological, energy, and mineral resources; and enhance and protect our quality of life."

The USGS maintains a database of global earthquake data. Using only that data from 1973 onward, the period of time when reliable global seismic networks were in operation to detect nuclear explosions, I discovered that the frequency of large earthquakes, magnitude $\geq 6$ and magnitude $\geq 7$, were increasing, as shown in Figure 9.
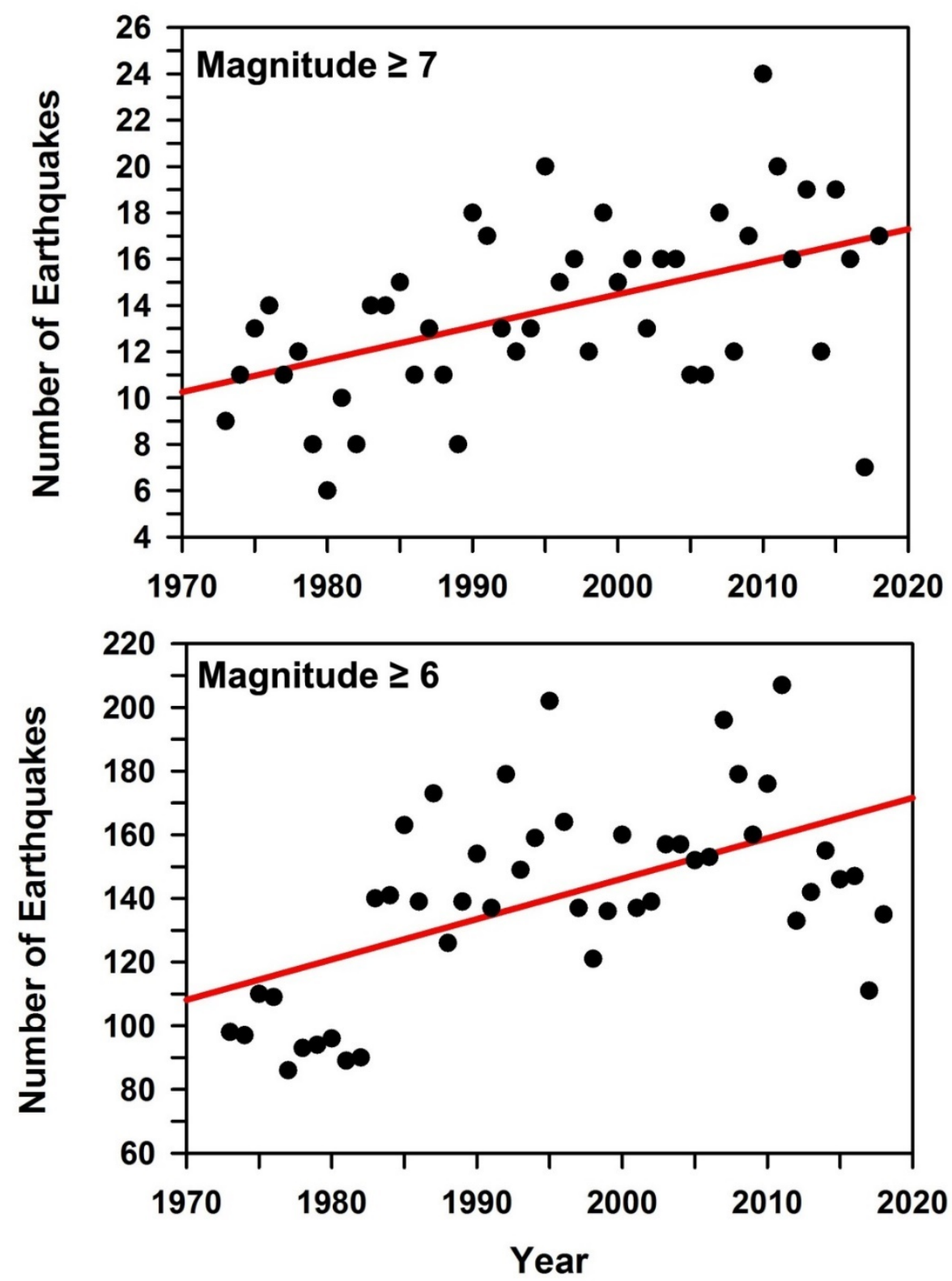

Figure 9. The annual number of earthquakes of the indicated magnitude from USGS data shown with linear regression fit lines. Adapted from [83]. 
Marcia K. McNutt, an Obama appointee, served as USGS Director 2009-2013. The question arises as to why neither she nor her predecessors warned the Japanese of the increasing frequency of large earthquakes. Perhaps, with such a warning, the Japanese might have been better prepared, and the Fukushima nuclear disaster might have been averted.

Poor science is often attended by deficient integrity. As Editor of Science magazine, following her USGS stint, McNutt proffered an editorial promoting the supposedly hypothetical future possibility of geoengineering [84]. The reality is that geoengineering has been ongoing with ever-increasing frequency, intensity, duration, and geographical range for years. I submitted a Prospective to Science on that subject but it was rejected without review [85]. There are further allegations of deficient integrity in her next stint as president of the National Academy of Sciences [86, 87].

The National Academy of Sciences should be a paragon of integrity and competence. It is neither. For example, I submitted a manuscript to Proceedings of the National Academy of Sciences (PNAS) entitled "New Evidence of Aerosolized Toxins in the Lower atmosphere." The PNAS editorial board rejected the paper without review because "it lacked the broad appeal necessary for further consideration by the journal."

There is an absurdity in the PLOS ONE article asserting "perceived losses of scientific integrity under the Trump Administration." Recall the old proverb: Those who live in glass houses should not throw stones.

\section{SYSTEMATICALLY IGNORED FUNDAMENTAL CONCEPTS: PARTICULATE-INHIBITED ATMOSPHERIC CONVECTION AS THE MAIN CAUSE OF GLOBAL WARMING}

For three decades the United Nations and complicit governmental institutions have been promoting the political-ideology that global warming is occurring, caused principally by atmospheric carbon dioxide and greenhouse gases trapping heat that should be radiated into space [88]. Not everybody agrees, some think global warming is either not occurring or else it is a natural phenomenon. It is neither.

In 2017, Bernard Gottschalk noticed a NOAA graph published in the New York Times, an image of a temperature profile that appeared to show a bump during World War II. He downloaded thermal data sets from the National Oceanic and Atmospheric Administration, performed sophisticated curve fitting and demonstrated that the World War II bump is a robust feature, which he attributed to human causes $[89,90]$.

Gottschalk's presentation was the first indication to me that global warming is mainly caused by particulate pollution as shown in Figure 10. Aerosol particles absorb radiation from the sun and from the earth, become heated, transfer that heat to the atmosphere, which reduces atmospheric convection, thus reducing surface heat loss, causing warming locally and/or globally [91-97]. I first submitted one of those papers [94] to the Proceedings of the National Academy of Sciences, but they rejected it without review. 
Herndon, J. M. (2020). Trump Administration Begins to Recognize the Loss of Scientific Integrity: Refuting a Political Hit job. Advances in Social Sciences Research Journal, 7(5) 283-303.

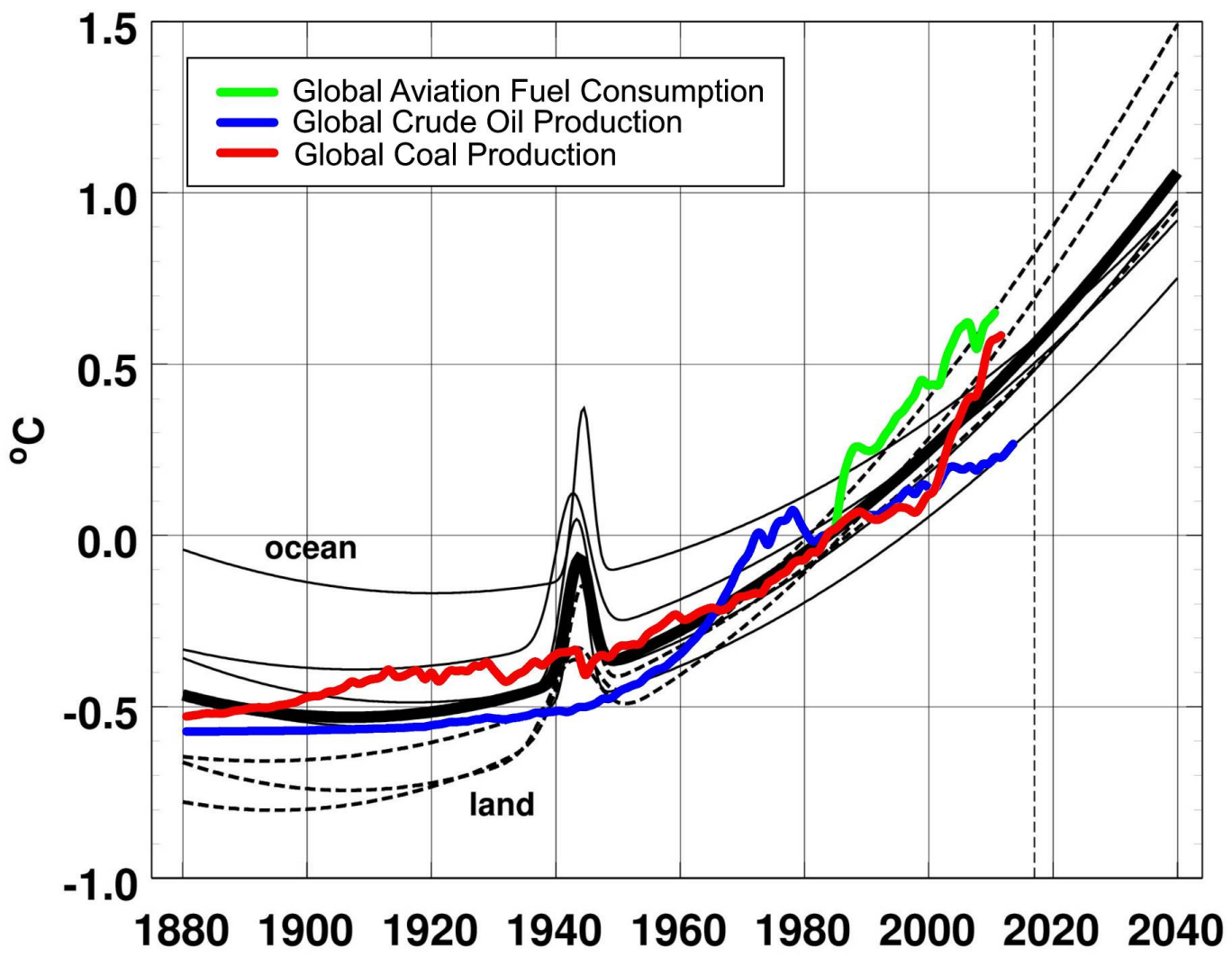

Figure 10. Copy of Gottschalk's fitted curves for eight NOAA data sets [89] showing the relative profiles over time to which I added proxies for particulate pollution. From [91].

There seems to be a widespread, prevalent disease in the scientific community called IDS, Integrity Deficit Syndrome. For thirty years, scientists involved with the United Nations' Intergovernmental Panel on Climate Change have assessed climate change without ever mentioning or taking into account the near-daily, near-global jet-emplacement of aerosol particulates into the atmosphere that cause global warming and which take place under auspices of a United Nations' Trojan horse treaty $[98,99]$. Tabulations of opinions have been used to deceive people regarding the aerial spraying $[100,101]$, but the reality is that the aerosol particulate emplacement harms human health [102-109] and is devastating to environmental health [96, 97, 103, 105, 110-115].

\section{CONCLUSIONS}

The tabulated opinions collected by Goldman et al. [1] are without merit. A scientific community, apparently suffering from Integrity Deficit Syndrome, cannot be expected to provide a truthful assessment, especially when queried about the actions of a president who might change the science landscape under which they flourish. The PLOS ONE paper [1], I allege, is no more than a political hit job aimed at damaging President Trump. Its consequence, however, was an inspiration for me to describe with clarity and truthfulness the deplorable state of integrity that exists in the scientific establishment. The breaches of scientific integrity described here, however, are just glimpses of even more pernicious, documented instances. 


\section{References}

1. Goldman, G.T., et al., Perceived losses of scientific integrity under the Trump administration: A survey of federal scientists. Plos one, 2020. 15(4): p. e0231929.

2. http://www.nuclearplanet.com/cv4.pdf.

3. Herndon, J.M., Some reflections on science and discovery. Curr. Sci., 2015. 108(11): p. 1967-1968.

4. Herndon, J.M., Make America Great Again in Science: A Guide for All Sovereign Nations. Advances in Social Sciences Research Journal, 2020. 7(4): p. 310-317.

5. Kuhn, T.S., The Structure of Scientific Revolutions1962, Chicago, IL, USA: University of Chicago Press.

6. Lehmann, I., P'. Publ. Int. Geod. Geophys. Union, Assoc. Seismol., Ser. A, Trav. Sci., 1936. 14: p. 87-115.

7. Birch, F., The transformation of iron at high pressures, and the problem of the earth's magnetism. Am. J. Sci., 1940. 238: p. 192-211.

8. Herndon, J.M., The nickel silicide inner core of the Earth. Proc. R. Soc. Lond, 1979. A368: p. 495-500.

9. Belonoshko, A.B., et al., Low viscosity of the Earth's inner core. Nature communications, 2019. 10(1): p. 1-7.

10. Jacobs, J., The Earth's inner core and the geodynamo: Determining their roles in the Earth's history. Eos, Transactions American Geophysical Union, 1995. 76(25): p. 249-253.

11. Jephcoat, A. and P. Olson, Is the inner core of the Earth pure iron? Nature, 1987. 325(6102): p. 332-335.

12. Merkel, S., et al., Raman spectroscopy of iron to 152 gigapascals: Implications for Earth's inner core. Science, 2000. 288(5471): p. 1626-1629.

13. Lincot, A., S. Merkel, and P. Cardin, Is inner core seismic anisotropy a marker for plastic flow of cubic iron? Geophysical Research Letters, 2015. 42(5): p. 1326-1333.

14. Herndon, J.M., The chemical composition of the interior shells of the Earth. Proc. R. Soc. Lond, 1980. A372: p. 149154.

15. Herndon, J.M., The object at the centre of the Earth. Naturwissenschaften, 1982. 69: p. 34-37.

16. Herndon, J.M., Feasibility of a nuclear fission reactor at the center of the Earth as the energy source for the geomagnetic field. J. Geomag. Geoelectr., 1993. 45: p. 423-437.

17. Herndon, J.M., Composition of the deep interior of the earth: divergent geophysical development with fundamentally different geophysical implications. Phys. Earth Plan. Inter, 1998. 105: p. 1-4.

18. Herndon, J.M., Geodynamic Basis of Heat Transport in the Earth. Curr. Sci., 2011. 101(11): p. 1440-1450.

19. Herndon, J.M., Terracentric nuclear fission georeactor: background, basis, feasibility, structure, evidence and geophysical implications. Curr. Sci., 2014. 106(4): p. 528-541.

20. Dziewonski, A.M. and D.A. Anderson, Preliminary reference Earth model. Phys. Earth Planet. Inter., 1981. 25: p. 297-356.

21. Keil, K., Mineralogical and chemical relationships among enstatite chondrites. J. Geophys. Res., 1968. 73(22): p. 6945-6976.

22. Kennet, B.L.N., E.R. Engdahl, and R. Buland, Constraints on seismic velocities in the earth from travel times Geophys. J. Int., 1995. 122: p. 108-124.

23. Herndon, J.M. and H.E. Suess, Can enstatite meteorites form from a nebula of solar composition? Geochim. Cosmochim. Acta, 1976. 40: p. 395-399.

24. Herndon, J.M., Solar System processes underlying planetary formation, geodynamics, and the georeactor. Earth, Moon, and Planets, 2006. 99(1): p. 53-99.

25. Herndon, J.M., Solar System formation deduced from observations of matter. https://arxiv.org/ftp/astroph/papers/0408/0408151.pdf 
Herndon, J. M. (2020). Trump Administration Begins to Recognize the Loss of Scientific Integrity: Refuting a Political Hit job. Advances in Social Sciences Research Journal, 7(5) 283-303.

26. Grossman, L., Condensation in the primitive solar nebula. Geochimica et Cosmochimica Acta, 1972. 36(5): p. 597619.

27. Anders, E., Chemical processes in the early solar system, as inferred from meteorites. Accounts of Chemical Research, 1968. 1(10): p. 289-298.

28. Larimer, J.W., Chemical fractionations in meteorites-I. Condensation of the elements. Geochimica et Cosmochimica Acta, 1967. 31(8): p. 1215-1238.

29. Herndon, J.M., Reevaporation of condensed matter during the formation of the solar system. Proc. R. Soc. Lond, 1978. A363: p. 283-288.

30. Petaev, M.I. and J.A. Wood, The condensation with partial isolation (CWPI) model of condensation in the solar nebula. Meteoritics \& Planetary Science, 1998. 33(5): p. 1123-1137.

31. Nakamura, T., et al., Condensation and aggregation of solar corundum and corundum-hibonite grains. Meteoritics \& Planetary Science, 2007. 42(7-8): p. 1249-1265.

32. Meibom, A., et al., Primitive FeNi metal grains in $\mathrm{CH}$ carbonaceous chondrites formed by condensation from a gas of solar composition. Journal of Geophysical Research: Planets, 1999. 104(E9): p. 22053-22059.

33. Blewett, D.T., et al., Hollows on Mercury: MESSENGER Evidence for Geologically Recent Volatile-Related Activity. Science, 2011. 333: p. 1859-1859.

34. Herndon, J.M., NASA: Politics above Science2018: amazon.com.

35. Herndon, J.M., Hydrogen geysers: Explanation for observed evidence of geologically recent volatile-related activity on Mercury's surface. Curr. Sci., 2012. 103(4): p. 361-361.

36. Herndon, J.M., New indivisible planetary science paradigm. Curr. Sci., 2013. 105(4): p. 450-460.

37. Fermi, E., Elementary theory of the chain-reacting pile. Science, Wash., 1947. 105: p. 27-32.

38. Herndon, J.M., Planetary and protostellar nuclear fission: Implications for planetary change, stellar ignition and dark matter. Proc. R. Soc. Lond, 1994. A455: p. 453-461.

39. Herndon, J.M., Sub-structure of the inner core of the earth. Proc. Nat. Acad. Sci. USA, 1996. 93: p. 646-648.

40. Herndon, J.M., Examining the overlooked implications of natural nuclear reactors. Eos, Trans. Am. Geophys. U., 1998. 79(38): p. 451,456.

41. Herndon, J.M., Nuclear georeactor origin of oceanic basalt ${ }^{3} \mathrm{He} /{ }^{4} \mathrm{He}$, evidence, and implications. Proc. Nat. Acad. Sci. USA, 2003. 100(6): p. 3047-3050.

42. Hollenbach, D.F. and J.M. Herndon, Deep-earth reactor: nuclear fission, helium, and the geomagnetic field. Proc. Nat. Acad. Sci. USA, 2001. 98(20): p. 11085-11090.

43. Herndon, J.M., Herndon's Earth and the Dark Side of Science2014: Printed by CreareSpace; Available at Amazon.com and through other book sellers.

44. Roth, A.S., et al., The primordial He budget of the Earth set by percolative core formation in planetesimals. Geochemical perspectives letters., 2019. 9: p. 26-31.

45. Elsasser, W.M., On the origin of the Earth's magnetic field. Phys. Rev., 1939. 55: p. 489-498.

46. Elsasser, W.M., Induction effects in terrestrial magnetism. Phys. Rev., 1946. 69: p. 106-116.

47. Elsasser, W.M., The Earth's interior and geomagnetism. Revs. Mod. Phys., 1950. 22: p. 1-35.

48. Herndon, J.M., Uniqueness of Herndon's georeactor: Energy source and production mechanism for Earth's magnetic field. https://arxiv.org/ftp/arxiv/papers/0901/0901.4509.pdf, 2009.

49. Herndon, J.M., Nuclear georeactor generation of the earth's geomagnetic field. Curr. Sci., 2007. 93(11): p. 14851487. 
50. Herndon, J.M., Nature of planetary matter and magnetic field generation in the solar system. Curr. Sci., 2009. 96(8): p. 1033-1039.

51. Mound, J., et al., Regional stratification at the top of Earth's core due to core-mantle boundary heat flux variations. Nature Geoscience, 2019. 12(7): p. 575-580.

52. Deguen, R. and M. Lasbleis, Fluid Dynamics of Earth's Core: Geodynamo, Inner Core Dynamics, Core Formation, in Fluid Mechanics of Planets and Stars2020, Springer. p. 129-212.

53. Herndon, J.M., Whole-Earth decompression dynamics. Curr. Sci., 2005. 89(10): p. 1937-1941.

54. Herndon, J.M., Energy for geodynamics: Mantle decompression thermal tsunami. Curr. Sci., 2006. 90(12): p. 16051606.

55. Herndon, J.M., New indivisible geoscience paradigm. arXiv.org/abs/1107.2149, 2011.

56. Herndon, J.M., Origin of mountains and primary initiation of submarine canyons: The consequences of Earth's early formation as a Jupiter-like gas giant. Curr. Sci., 2012. 102(10): p. 1370-1372.

57. Herndon, J.M., Fictitous Supercontinent Cycles. arXiv.org/abs/1302.1425, 2013.

58. Herndon, J.M., A new basis of geoscience: whole-Earth decompression dynamics. New Concepts in Global Tectonics, 2013. 1(2): p. 81-95.

59. Herndon, J.M., Fictitious Supercontinent Cycles. Journal of Geography, Environment and Earth Science International, 2016. 7(1): p. 1-7.

60. Oliphant, M.L., P. Harteck, and E. Rutherford, Transmutation effects observed with heavy hydrogen. Nature, 1934. 133: p. 413.

61. Bethe, H.A. and C.L. Critchfield, The formation of deuterons by proton combination. Physical Review, 1938. 54(4): p. 248.

62. Bethe, H.A., Energy production in stars. Phys. Rev., 1939. 55(5): p. 434-456.

63. Gamow, G. and E. Teller, The rate of selective thermonuclear reactions. Phys. Rev., 1938. 53: p. 608-609.

64. Stahler, S.W., et al., The early evolution of protostellar disks. Astrophys. J., 1994. 431: p. 341-358.

65. Larson, R.B., Gravitational torques and star formation. Mon. Not. R. astr. Soc., 1984. 206: p. 197-207.

66. Levée, R.D., A gravitational contracting model. Astrophys. J., 1953. 117: p. 200-210.

67. Galloway, D.K., et al., The Influence of Stellar Spin on Ignition of Thermonuclear Runaways. The Astrophysical Journal Letters, 2018. 857(2): p. L24.

68. Lamers, H.J. and E.M. Levesque, Understanding Stellar Evolution2017: IoP Publishing.

69. Deboer, R., et al., The $\mathrm{C} 12(\alpha, \gamma) 016$ reaction and its implications for stellar helium burning. Reviews of Modern Physics, 2017. 89(3): p. 035007.

70. Rubin, V.C., The rotation of spiral galaxies. Science, 1983. 220: p. 1339-1344.

71. Lynden-Bell, D. and J.P. O'Dwyer, One mass-relation for planets, white dwarfs, and neutron stars. arXiv.org/abs/astroph/0104450, 2008.

72. Herndon, J.M., Thermonuclear ignition of dark galaxies. https://arxiv.org/ftp/astroph/papers/0604/0604307.pdf, 2006.

73. Herndon, J.M., New concept for internal heat production in hot Jupiter exo-planets, thermonuclear ignition of dark galaxies, and the basis for galactic luminous star distributions. Curr. Sci., 2009. 96: p. 1453-1456.

74. Herndon, J.M., Inseparability of science history and discovery. Hist. Geo Space Sci., 2010. 1: p. 25-41.

75. Herndon, J.M., Maverick's Earth and Universe2008, Vancouver: Trafford Publishing. ISBN 978-1-4251-4132-5. 
Herndon, J. M. (2020). Trump Administration Begins to Recognize the Loss of Scientific Integrity: Refuting a Political Hit job. Advances in Social Sciences Research Journal, 7(5) 283-303.

76. Moster, B.P., T. Naab, and S.D. White, emerge-an empirical model for the formation of galaxies since $\mathrm{z} \sim 10$. Monthly Notices of the Royal Astronomical Society, 2018. 477(2): p. 1822-1852.

77. Sparre, M., et al., (Star) bursts of FIRE: observational signatures of bursty star formation in galaxies. Monthly Notices of the Royal Astronomical Society, 2017. 466(1): p. 88-104.

78. Lagos, C.d.P., et al., The Fundamental Plane of star formation in galaxies revealed by the EAGLE hydrodynamical simulations. Monthly Notices of the Royal Astronomical Society, 2016. 459(3): p. 2632-2650.

79. Herndon, J.M., New concept for internal heat production in hot Jupiter exo-planets. https://arxiv.org/ftp/astroph/papers/0612/0612603.pdf 2006.

80. Herndon, J.M., Evidence contrary to the existing exo-planet migration concept. https://arxiv.org/ftp/astroph/papers/0612/0612726.pdf, 2006.

81. Cyr, K.E., W.D. Sears, and J.I. Lunine, Distribution and evolution of water ice in the solar nebula: Implications for solar system body formation. Icarus, 1998. 135(2): p. 537-548.

82. Corredoira, M.L., The twilight of the scientific age2013: Universal-Publishers.

83. Herndon, J.M., Evidence of variable Earth-heat production, global non-anthropogenic climate change, and geoengineered global warming and polar melting. J. Geog. Environ. Earth Sci. Intn., 2017. 10(1): p. 16.

84. McNutt, M., Ignorance is not an option. Science, 2015. 347(6228): p. 1293.

85. http://nuclearplanet.com/scimag.html

86. Herndon, J.M., An open letter to members of AGU, EGU, and IPCC alleging promotion of fake science at the expense of human and environmental health and comments on AGU draft geoengineering position statement. New Concepts in Global Tectonics Journal, 2017. 5(3): p. 413-416.

87. mcnutt1, http://www.nuclearplanet.com/mcnutt1.pdf.

88. Stocker, T., et al., IPCC, 2013: Climate Change 2013: The Physical Science Basis. Contribution of Working Group I to the Fifth Assessment Report of the Intergovernmental Panel on Climate Change, 1535 pp, 2013, Cambridge Univ. Press, Cambridge, UK, and New York.

89. Gottschalk, B., Global surface temperature trends and the effect of World War II: a parametric analysis (long version). arXiv preprint arXiv:1703.06511.

90. Gottschalk, B., Global surface temperature trends and the effect of World War II. arXiv preprint arXiv:1703.09281.

91. Herndon, J.M., Air pollution, not greenhouse gases: The principal cause of global warming. J. Geog. Environ. Earth Sci. Intn., 2018. 17(2): p. 1-8.

92. Herndon, J.M., Scientific misrepresentation and the climate-science cartel. J. Geog. Environ. Earth Sci. Intn., 2018. 18(2): p. 1-13.

93. Herndon, J.M., Fundamental climate science error: Concomitant harm to humanity and the environment J. Geog. Environ. Earth Sci. Intn., 2018. 18(3): p. 1-12.

94. Herndon, J.M., Role of atmospheric convection in global warming. J. Geog. Environ. Earth Sci. Intn., 2019. 19(4): p. 1-8.

95. Herndon, J.M., World War II holds the key to understanding global warming and the challenge facing science and society. J. Geog. Environ. Earth Sci. Intn., 2019. 23(4): p. 1-13.

96. Herndon, J.M. and M. Whiteside, Further evidence that particulate pollution is the principal cause of global warming: Humanitarian considerations. Journal of Geography, Environment and Earth Science International, 2019. 21(1): p. 1-11.

97. Herndon, J.M. and M. Whiteside, Geophysical consequences of tropospheric particulate heating: Further evidence that anthropogenic global warming is principally caused by particulate pollution. Journal of Geography, Environment and Earth Science International, 2019. 22(4): p. 1-23. 
98. Herndon, J.M. and M. Whiteside, Global Environmental Warfare. Advances in Social Sciences Research Journal, 2020. in press.

99. Herndon, J.M., M. Whiteside, and I. Baldwin, The ENMOD treaty and the sanctioned assault on agriculture and human and environmental health. Agrotechnology, 2020. 9(191): p. 1-9.

100. Shearer, C., et al., Quantifying expert consensus against the existence of a secret large-scale atmospheric spraying program. Environ. Res. Lett., 2016. 11(8): p. p. 084011.

101. Tingley, D. and G. Wagner, Solar geoengineering and the chemtrails conspiracy on social media. Palgrave Communications, 2017. 3(1): p. 12.

102. Herndon, J.M., Aluminum poisoning of humanity and Earth's biota by clandestine geoengineering activity: implications for India. Curr. Sci., 2015. 108(12): p. 2173-2177.

103. Herndon, J.M. and M. Whiteside, Further evidence of coal fly ash utilization in tropospheric geoengineering: Implications on human and environmental health. J. Geog. Environ. Earth Sci. Intn., 2017. 9(1): p. 1-8.

104. Herndon, J.M. and M. Whiteside, Geoengineering: The deadly new global "Miasma". Journal of Advances in Medicine and Medical Research, 2019. 29(12): p. 1-8.

105. Herndon, J.M. and M. Whiteside, Unacknowledged potential factors in catastrophic bat die-off arising from coal fly ash geoengineering. Asian Journal of Biology, 2019. 8(4): p. 1-13.

106. Whiteside, M. and J.M. Herndon, Coal fly ash aerosol: Risk factor for lung cancer. Journal of Advances in Medicine and Medical Research, 2018. 25(4): p. 1-10.

107. Whiteside, M. and J.M. Herndon, Aerosolized coal fly ash: Risk factor for neurodegenerative disease. Journal of Advances in Medicine and Medical Research, 2018. 25(10): p. 1-11.

108. Whiteside, M. and J.M. Herndon, Aerosolized coal fly ash: Risk factor for COPD and respiratory disease. Journal of Advances in Medicine and Medical Research, 2018. 26(7): p. 1-13.

109. Whiteside, M. and J.M. Herndon, Geoengineering, coal fly ash and the new heart-Iron connection: Universal exposure to iron oxide nanoparticulates. Journal of Advances in Medicine and Medical Research, 2019. 31(1): $\mathrm{p}$. $1-20$.

110. Herndon, J.M., Adverse agricultural consequences of weather modification. AGRIVITA Journal of agricultural science, 2016. 38(3): p. 213-221.

111. Herndon, J.M. and M. Whiteside, Contamination of the biosphere with mercury: Another potential consequence of on-going climate manipulation using aerosolized coal fly ash J. Geog. Environ. Earth Sci. Intn., 2017. 13(1): p. $1-11$.

112. Herndon, J.M. and M. Whiteside, California wildfires: Role of undisclosed atmospheric manipulation and geoengineering. J. Geog. Environ. Earth Sci. Intn., 2018. 17(3): p. 1-18.

113. Whiteside, M. and J.M. Herndon, Previously unacknowledged potential factors in catastrophic bee and insect dieoff arising from coal fly ash geoengineering Asian J. Biol., 2018. 6(4): p. 1-13.

114. Whiteside, M. and J.M. Herndon, Aerosolized coal fly ash: A previously unrecognized primary factor in the catastrophic global demise of bird populations and species. Asian J. Biol., 2018. 6(4): p. 1-13.

115. Whiteside, M. and J.M. Herndon, Role of aerosolized coal fly ash in the global plankton imbalance: Case of Florida's toxic algae crisi. Asian Journal of Biology, 2019. 8(2): p. 1-24. 